\title{
Mapping the Adult Numeracy Curriculum: Cultural Capital and Conscientization
}

\author{
HELEN OUGHTON
}

\begin{abstract}
This study explores learners' accounts of what they want from an adult numeracy curriculum, using mindmaps to construct and present a snapshot of their current conceptions of the curriculum. Analysis of the resulting maps finds that for most participants, the desired curriculum is constructed in terms of school mathematics. However, for one group, exposed to wider issues of social justice, the curriculum is constructed in terms of situated practice and financial literacy. The discussion draws on Bernstein's theories of curriculum and ideology; Freire's conscientization; and research on adults' motivations for learning numeracy. It is suggested that most learners in this study value the cultural capital associated with school mathematics, and that these learners wish to engage with the challenge set by school mathematics. However, a minority of learners appeared to undergo a process of conscientization, formulating ideas for a numeracy curriculum relevant to adults' lives.
\end{abstract}

\section{Introduction}

The question: 'What do learners want from the adult numeracy curriculum?' is many-layered and complex. In this short, exploratory study, I asked learners in the adult numeracy classes I teach to use mindmaps to represent their ideas about what they would like the curriculum to be. While my results do not (and cannot) fully answer my question, they do provide insights into adult numeracy learners' beliefs and aspirations.

I begin this paper with a brief background to the ideology of adult numeracy curriculum development, making reference to the Adult Numeracy Core Curriculum in England (BSA 2001). In the second section, I describe the study and its outcomes, introducing the use of mindmaps as research tools, and reporting on the ways in which the participating learners discussed and constructed their mindmaps. In my concluding discussion, I draw on Bernstein's theories of recontextualisation, curriculum and ideology; Freire's concepts of domestication and conscientization; and recent research on adults' motivations for attending numeracy classes.

As an exploratory study, my findings inevitably raised more questions than they answered. From the outset, it was clear that I would not be able to identify what participants wanted in the adult numeracy curriculum, but only 
obtain their accounts of what they wanted. Questions arose about the extent to which learners' accounts reflected their beliefs and perceptions; about power structures between researcher and researched (and between teacher and student); and about the socio-cultural processes which led to the participants giving the accounts they did.

In particular, the study raised the question of whether it is possible to construct a curriculum to meet learners' interests - or whether learners' interests are instead constructed by the existing curriculum.

\section{Background: Ideology and the adult numeracy curriculum in England}

National curricula for adult literacy, language and numeracy were introduced in England for the first time as part of the Skills for Life strategy (BSA 2001, DfES 2001), and are based closely on the National Curriculum for schools. Although the adult curriculum documents claim not to be prescriptive, they are closely linked to a system of national qualifications and, since funding is dependent on learners' achievement of these qualifications, the curricula are thus made obligatory for all funded provision.

While the Skills for Life strategy has significantly raised the profile of adult numeracy and literacy in England, there have been many concerns about its neo-liberal emphasis on economic effectiveness and the functional model it assumes for literacy and numeracy. The ideology of Skills for Life has been critiqued for its deficit model of adult learners, and the assumption that literacy and numeracy can be viewed as a set of autonomous skills which can be transferred unproblematically to different contexts of use in adult lives (Baker 2005, Papen 2005, Coben 2006, Oughton 2007).

The difficulty of transferring autonomous numeracy skills to real-life situations has long been recognised. For example, Lave (1988) found that adults' numeracy practices while grocery shopping and dieting bore little relationship to classroom mathematics. Evans and Tsatsaroni (2000) criticise the simplistic notion that giving real world 'contexts' for mathematical concepts provides meaning for students. In a study of adults' attitudes to measurement in numeracy provision, Baxter et al (2006) suggest that many adults have sophisticated situated measurement practices and that the learning of measurement as it is presented by the current curriculum is not relevant to adult lives. Benn (2001) discusses the relationship between mathematics education and citizenship and highlights a mismatch between the traditional curriculum and the needs of active citizenship.

The underlying assumption of the adult numeracy curriculum, that learners need to acquire 'functional' numeracy to help them in their daily lives, is challenged in a study by (Swain et al 2005, Swain 2005) which concluded that one of the main reason adults wish to learn numeracy is: 
to prove to themselves that they have the ability to study and succeed in a high-status subject, which they perceive to be a signifier of intelligence. The other main reasons are for learners to help their children, and for understanding, engagement and enjoyment. (Swain 2005:305)

Dowling (1998) categorises mathematical activity into a hierarchy that exists between the superior intellectual (the esoteric domain) and the inferior manual (the public domain). Dowling shows how lower-level students are constructed as engaged in 'everyday' practices and are excluded from esoteric mathematical practices. The study by Swain et al (2005) suggests that, while most adult numeracy learning is restricted to the public domain, many adult numeracy learners aspire to the esoteric domain. Tomlin (2002) also challenges the assumption that adult numeracy should be functional.

Lerman (2000) applies Bernstein's theories of recontextualisation and ideology to mathematics education, and suggests that curriculum development may be driven by: an authoritarian view, which involves the 'selection of culturally valued knowledge'; a neo-liberal view, 'producing citizens prepared for useful, wealth producing lives'; an 'old-liberal' agenda of enabling people to fulfil their lives; or a radical agenda of preparing people to critique and change their world. He also acknowledges the role of 'inertia', pointing out that much of the mathematics curriculum in England is very similar to that of 50 years ago (Lerman 2000:30, Bernstein 1996). It is on this 50 year-old school mathematics curriculum that the adult numeracy curriculum is largely based.

\section{The Mindmap Study}

In planning this research, I recognised that I could only obtain accounts of what participating learners want from the curriculum. Moreover, I believed that those accounts would vary widely depending on the investigative approach taken. For example, ideas generated in a focus group would be very different from responses to a Likert-style questionnaire, and a long-running action research project would produce different outcomes again.

Silverman (2000) emphasises the value of unexpected responses. I felt that at this exploratory stage, the approach that would give the most interesting outcomes would be one which enabled participants' accounts to be as unstructured, as unprompted and as spontaneous as possible. I decided that one way to achieve such a response would be to ask adult learners to draw a mindmap (Buzan 1993) to represent the curriculum they wanted.

The type of mindmap used in this study is sometimes referred to as a brainstorming mindmap (e.g. Anderson-Inman and Ditson 1998) since it provides a graphical, non-linear and non-sequential means of recording and 
representing ideas, without the need for establishing a hierarchy or sequential structure. As such, I intended that the mindmaps would provide a relatively unpremeditated snapshot of each learner's ideas at the time they participated in the study (recognising that learners' conceptions of the curriculum are likely to develop and change as they progress through their numeracy courses).

I hoped that the learners' mindmaps would help me learn more about:

- whether the learners I work with perceive their ideal numeracy curriculum to be constructed in terms of situated practices, or in terms of autonomous classroom mathematics; and

- $\quad$ any recurrent themes in the mindmaps which might be unexpected or challenge current assumptions about the adult numeracy curriculum.

It is inevitable that my investigation draws somewhat on critical theory. I work with adults who have been failed by educational systems in the past, who are constructed within a deficit model by the Skills for Life strategy, and whose voices are seldom heard. In a critical analysis of the Adult Numeracy Core Curriculum in England (Oughton 2007), I attempted to expose the ideology and power structures that underlie the current curriculum, and one aim of this study was to give learners a voice in curriculum reform. According to Cohen et al (2007:31) curriculum research has been one area of research where critical theory has had most impact:

Not all knowledge can be included in the curriculum; the curriculum is a selection of what is deemed to be worthwhile knowledge. The justification for that selection reveals the ideologies and power in decision-making in society.

\section{Mindmapping as a Research Tool}

Mindmapping was popularised as a personal development tool by Buzan (1993). The idea was developed from an earlier and related form of representation, 'concept mapping', developed by Novak and Gowin (1984) to help learners increase their understanding. Anderson-Inman and Ditson $(1998,1999)$ also used concept mapping as a tool for teachers to negotiate meanings with learners.

Mindmaps, concept maps and other forms of multimodal representation have been used as educational research tools in several recent studies. According to Kress et al (2004:2) a multimodal approach is 'one where attention is given to all the culturally shaped resources that are available for making meaning'. Kress and Mavers (2004:172) suggest that 'language alone can no longer give us full access to the meanings of most contemporary messages, which are now constituted in several modes ... [Each mode] is a partial bearer of meaning only'. They ask whether 
different modes provide different affordances, to be taken up and used differently by different cultural groups.

Pearson and Somekh (2000) and Mavers et al (2002) use concept maps as a means to examine school students' mental models of networked technologies. They suggest that their methods are closer to Buzan's notion of a mindmap as reflecting the internal processes of 'radiant thinking' (Buzan 1993). The concept maps, consisting of drawings linked by lines, provide the researchers with 'momentary, static snapshots of the dynamic processes of the pupils' current concepts of computers in their world' (Mavers et al 2002: 189).

Mannion and Ivanič (2007) explore a number of graphical and spatial metaphors which enable them to map the terrain of literacies within further education settings, and suggest that the map itself becomes another object of inquiry. In piloting their methods, Mannion and Ivanič discovered that while conventional methods of inquiry encouraged a deficit view of literacy, the spatial approaches made students more aware of their own literacy practices.

Although mindmaps are not widely discussed in the literature of educational research methodology, many of the considerations associated with other types of qualitative data apply equally to my participants' mindmaps. For example, issues raised by Silverman (2001) and Baker (1982, cited in Silverman 2001) would also apply to data in the form of a mindmap:

1. What is the relation between interviewees' accounts and the world they describe? Are such accounts potentially 'true' or 'false' or is neither concept always appropriate to them?

2. How is the relation between interviewer and interviewee to be understood? (Silverman 2001:86)

Baker (1997:163) suggests that such processes are better described 'not as data "collection", but rather as...data "generation" '. Certainly, as they drew their mindmaps, the learners participating in my study appeared to be constructing, rather than recording, their ideas and their accounts of them. This resonates with Edwards and Usher (2000:138) who suggest that 'meaning is made through mapping rather than found'.

\section{Adult Learners Participating in the Project}

The participants in the project were 21 learners based at an adult community education centre in Derbyshire, England. All were attending discrete (rather than embedded) adult numeracy classes, studying at a range of levels from Entry Level to Level $2^{1}$. All were self-motivated, and none were under external obligation to attend (such as employers' requirements or probation service orders). Sixteen of the group were women and five were men, a gender imbalance typical of this day-time community provision. 
The sample could be described as a convenience sample, consisting of all the learners attending four of the classes I teach at the adult community education centre. However, I have no reason to consider my sample atypical of this type of provision.

Three of the four participating groups in the study were based at the adult education centre, with students working at different levels within one group. Students can join these classes at any time throughout the year, and the most recent learners had joined their classes only two weeks before participating in this study, while others had been studying numeracy at the centre for over a year. These three groups are referred to in this report as A, B and C. By contrast, Group D meets at an outreach centre, and is provided for students on teaching assistant and childcare training courses. Although it, too, is officially a 'roll-on-roll-off' class, the students in group D had all been attending for between four and six months, and were all working at a higher level (Level 2) when they took part in the study.

\section{Greating the Mindmaps}

The participants created their mindmaps during the course of their usual adult numeracy classes, allowing opportunities to discuss the project in these groups. I decided that richer ideas might be yielded if learners were able to talk to each other as they drew their mindmaps, and I also thought that this might make the project less daunting for some of the least confident participants. I did consider recording these accompanying conversations, as I felt that they would reveal as much about participants' attitudes, priorities and beliefs as the mindmaps themselves. However, eventually I decided that for a small, informal study such as this one, a recording device would be unnecessarily inhibiting and intrusive, and might have prevented some of the less confident and more vulnerable learners from participating. The four participating groups took up the opportunity for discussion to widely differing extents, as described later in the report.

For each group, I asked the participants to draw a mindmap to show what they, personally, would like to see in the numeracy curriculum. I emphasised that while I was happy for them to discuss their thoughts with their fellow students, I wanted them to represent their own ideas on their own mindmaps.

In order to illustrate the mindmap process to the participants before they started, but to avoid directing the participants more than was necessary, I demonstrated using a possible mindmap for an adult literacy curriculum. Since I was particularly interested in whether learners conceived the curriculum in terms of situated practices or autonomous skills, I gave examples from both models, including writing a letter as a situated literacy event, and spelling and punctuation as autonomous literacy topics. 
Participants were then given a large sheet of paper, a drawing pen and as much time as they needed to complete their mindmaps. While they did so, I observed the process, listened to their discussions and made brief notes. Once the mindmaps were completed, I gave the participants highlighter pens and talked them through a system of colour-coding to show why they felt each curriculum idea was important to them. The reasons they could choose were:

1. needed for everyday life

2. needed for work

3. needed to help your children

4. needed for a qualification

5. topics you have always wanted to understand.

Participants could give more than one reason for each curriculum idea, and in many cases chose to give all five to some of their ideas.

\section{The Resulting Mindmaps}

All of the participants appeared to be familiar with the concept of mindmaps, and showed little hesitation about how to use this as a form of representation. Many of the participants seemed to enjoy drawing their mindmaps and several clearly took pride in how they presented them. They were particularly pleased by how attractive the mindmaps looked with the colour coding (see Figure 1).

Nonetheless, some participants expressed anxiety that they would write the 'wrong' thing, or something that might be considered stupid. It seems likely that further participants also felt this anxiety, but chose not to express it. Although participants were asked to put down their own thoughts, and I emphasised that all ideas were valid, there appeared to be some self-consciousness and concern to 'get it right'. For example, Emma², who is under 20 and attends the same numeracy class as her mother, seemed to lack the confidence to draw her own mindmap and instead copied her mother's mindmap in almost exact detail.

In Groups A, B and C, most participants chose to draw their mindmaps without much discussion among themselves. Any discussion was limited to quiet comparisons with their neighbours. For example, in Group A, Claire and Analice drew their mindmaps together. These two young women work in the same residential care home and are friends. They discussed the way they used numeracy in their work, for example for recording the weight and height of the elderly residents in their care. However, they did not represent these situated practices on their mindmaps. 


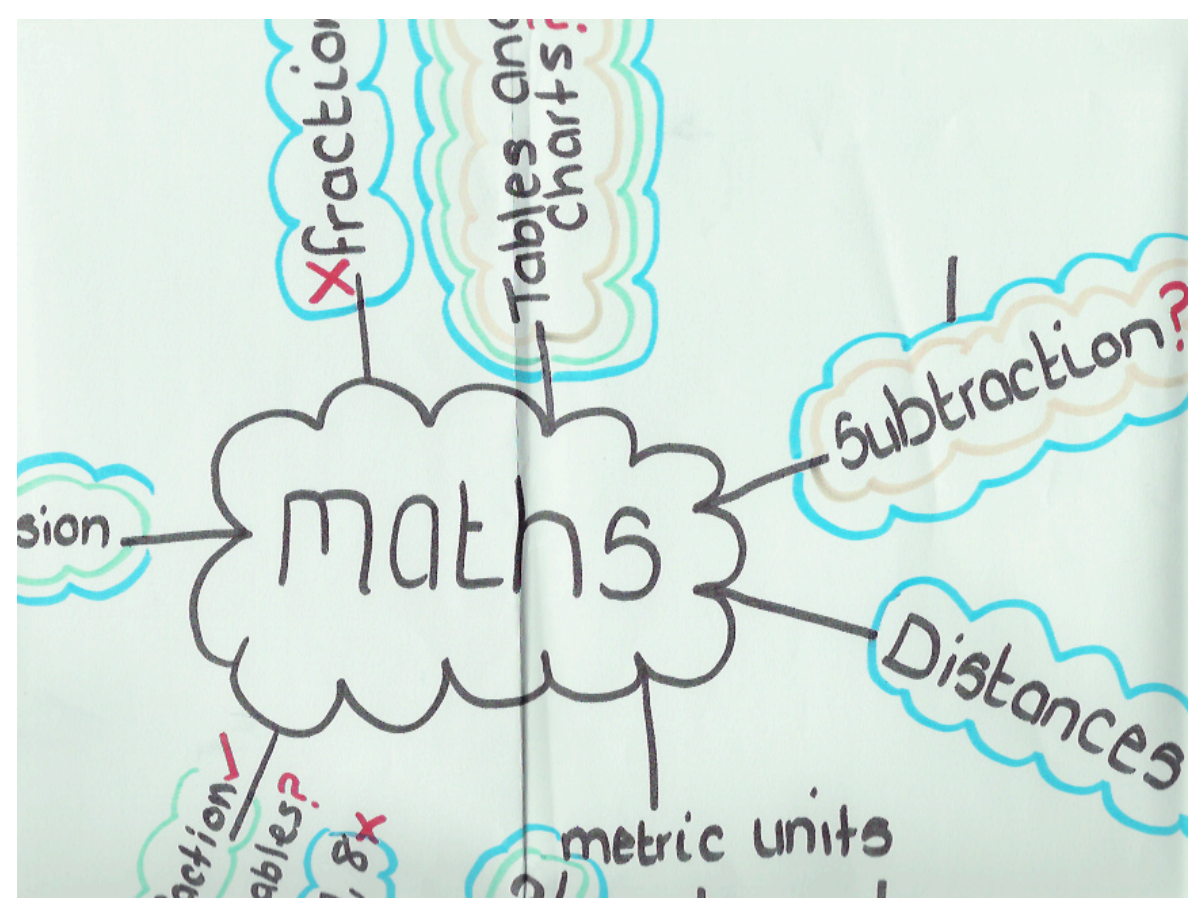

Figure 1: Part of Glaire's mindmap, showing the evident pride she took in presentation

In Group D, something different happened. As explained earlier, Group D is a small group of learners all working at Level 2, and the learners in the group are working towards childcare and teaching assistant qualifications, perhaps giving them greater opportunities for reflection on curriculum and classroom discourse. As soon as the mindmap task was explained to them, the participants in this group began an enthusiastic and spontaneous discussion of the role of numeracy in everyday life. There was particular interest in welfare benefits, budgeting and personal finance, and issues of social justice were raised. The resulting mindmaps reflected this discussion, and are analysed in more detail later.

\section{Analysing the Mindmaps}

In analysing the learners' mindmaps I had two objectives: to examine whether the learners' mindmaps represented the numeracy curriculum in terms of a situated practice, or in terms of autonomous classroom mathematics; and to look for any recurrent themes in the mindmaps which might be unexpected or challenge current assumptions about the adult numeracy curriculum. 
The categorisation of the ideas on the mindmaps into themes or codes was more straightforward than I had anticipated because many of the participants, particularly those whose mindmaps were based on classroom mathematics, had used topic headings familiar from the discourse of classroom mathematics, for example 'fractions' or 'addition'. This tendency for participants to construct all numeracy practices, including socially situated practices, in terms of school numeracy has been noted by Tomlin et al (2002). Those who represented situated practices on their mindmaps often used simple, recurrent terms such as 'DIY' or 'Money'.

Deciding whether or not an idea on a mindmap should be categorised as a 'situated practice' was more problematic. For example, the term 'measurement' can indeed be used to describe a situated practice, but is also widely used as a title for a curriculum topic, where it may be used for socially meaningless activities such as measuring the lengths of abstract shapes printed on a worksheet. I decided that in such cases, the deciding factor should be whether or not a social context was provided for the activity. Thus 'measurement' alone was categorised as autonomous, but 'measuring curtains', was categorised as a situated practice. Similarly 'percentages' was categorised as autonomous, but 'percentage discount' as a situated practice.

\section{Results of Analysis}

Table 1 in the appendix to this paper shows the results of my analysis in tabulated form.

For the majority of learners in Groups A, B and C, the mindmaps showed curricula constructed primarily in terms of autonomous mathematics. Topic headings were taken from the discourse of the classroom and the textbook: for example, 'addition', 'multiplication', 'fractions', 'percentages', 'statistics', 'shape and space'. George's mindmap (Figure 2) was an example of this.

Percentages and fractions were among the most commonly recurring topics. Each appeared on fourteen out of the twenty one mindmaps, and all but four of the mindmaps included one or the other. Many of the participants used the colour coding scheme to represent multiple reasons for wanting to learn these two topics. Often, they were topics the participants had 'always wanted to understand'. Seven of the learners put 'times tables' (memorised multiplication facts up to ten multiplied by ten) on their mindmaps; to me, it was unexpected and significant that for six of these learners, this was a topic they had 'always wanted to understand'. Possible reasons for this are discussed later. Other common topics included addition, subtraction, multiplication, division, decimals and metric measurements of length. 


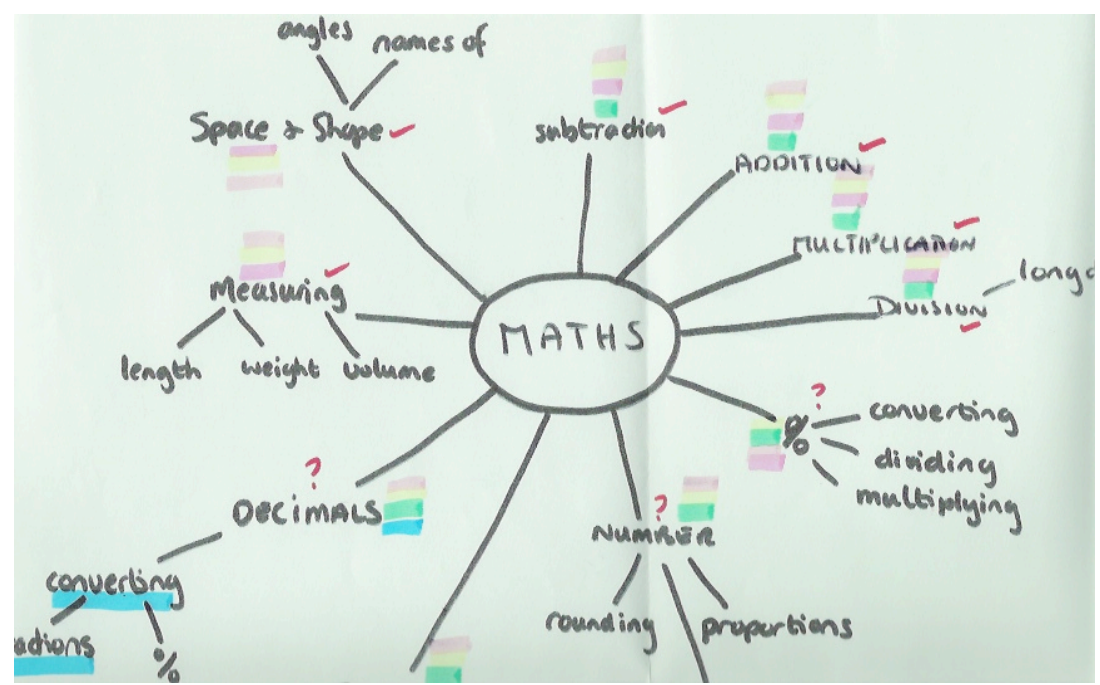

Figure 2: George's mindmap, representing a curriculumbased on classroom mathematics

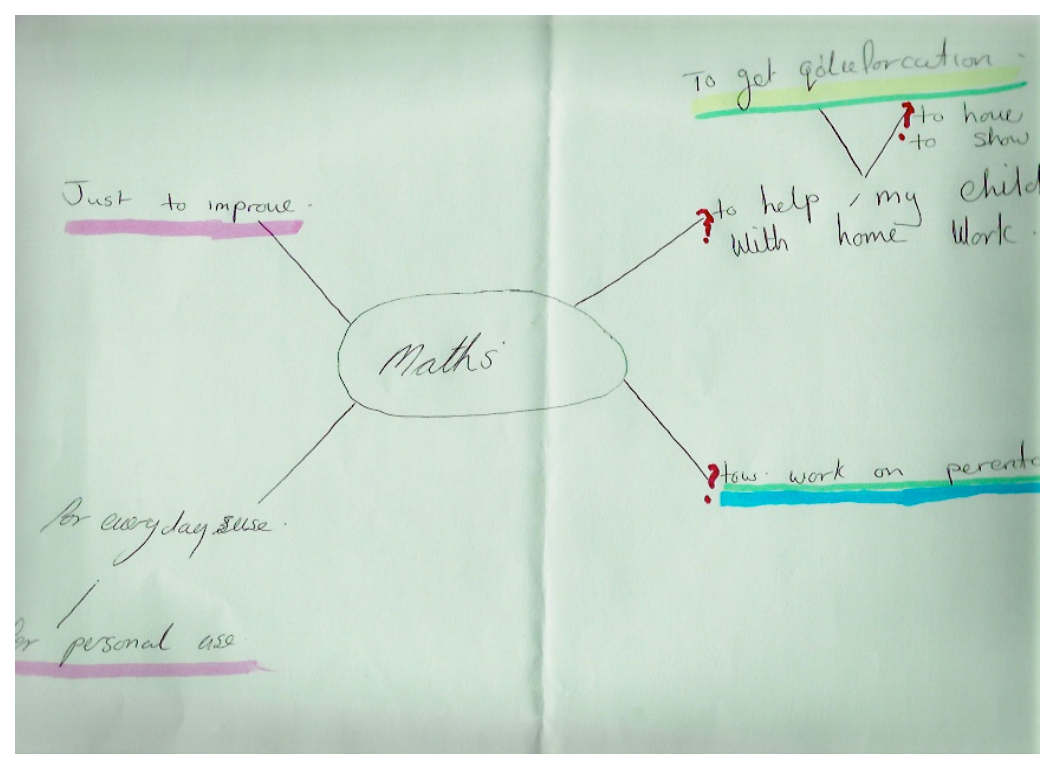

Figure 3: Liz's mindmap. Liz represents her motivations for studying numeracy. The only numeracy topic she mentions is percentages, and the blue colour coding shows this to be one she regards as a personal challenge.

Overall patterns also emerged in the reasons learners gave for wanting to learn each numeracy topic. The most common reasons were 
'needed for everyday life', 'needed for a qualification' and 'have always wanted to understand'. The least common reason was 'needed for work'. If this last trend is representative of adult numeracy learners as a whole, it has significant implications for government policy in England, which has an economically effective workforce as one of its primary goals. However, this finding may merely reflect the fact that the sample was small and taken from day-time numeracy classes in which most learners either do not work outside the home, or do so only on a part-time basis.

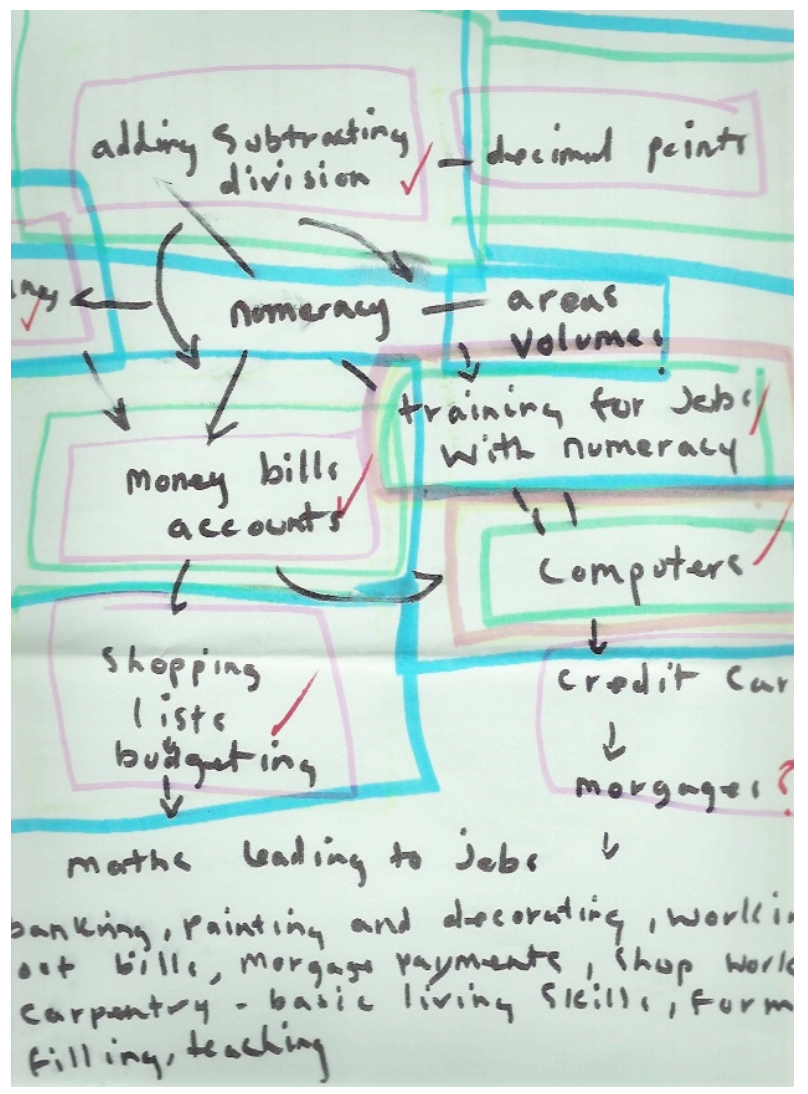

Figure 4: Bob's mindmap illustrates Group D's flow of ideas about situated numeracy practices. Eventually there were too many ideas to fit into the mindmap structure and he has just jotted them down at the bottom.

Oscar and Liz, both in Group C, took a different approach to their mindmaps. They chose to use them to represent their motivations for studying numeracy. It emerged that many other participants had included motivations alongside the numeracy topics they wanted to cover. Helping their children, gaining a qualification and improving career prospects were recurrent themes. 
However, for me, the most interesting result of my analysis was the difference between the mindmaps produced by Group D, who - as described earlier - held a spontaneous and enthusiastic discussion about numeracy in everyday life, and the mindmaps produced by the other three groups, who engaged in little or no discussion.

Drawing on their discussion, the participants in Group D expressed their ideal curriculum almost entirely in terms of situated practices, which included: shopping, finance, budgeting, cooking, making curtains, painting and carpentry (see Figure 4 above).

\section{Discussion}

In the following section, I draw on ideas from Bernstein, Bourdieu and Freire, together with research on adults' motivations for studying numeracy, to examine how adult numeracy learners' interests are constructed and, in particular, to suggest possible reasons for the differences between the mindmaps produced by Groups A, B and C, and the mindmaps produced by Group D.

According to Bernstein (1975:85), 'curriculum defines what counts as valid knowledge'. He argues that the recontextualisation of a practice, from its original site to curriculum and pedagogy, opens up a space in which ideology inevitably plays a role in selecting what is to be learnt from the total knowable (Bernstein 1996).

In the first part of my discussion, I draw on socio-cultural models of numeracy and ideological critique to explore possible reasons why the learners in Groups A, B and C tended to represent their curriculum needs in terms of autonomous classroom mathematics. I then consider why those in Group D took such a different approach, and what factors led to this difference. Again, socio-cultural issues and ideology will be considered.

\section{Groups A, B and C: Interests Constructed by the Gurriculum}

What led to the learners in Groups A, B and C representing on their mindmaps a collection of topics taken from the dominant discourse of school mathematics curricula? A naturalistic approach might be to take these participants' accounts as reflections of the world 'as it is'. The conclusion from such a perspective might be that the current curriculum covers exactly what these adult numeracy learners want and need to learn.

In my view, this would be a misleading over-simplification. Instead, I believe we need to consider the value placed on cultural capital (Bourdieu 2003). Dowling (1998) discusses the cultural capital associated with qualifications and proficiency in the 'esoteric domain' of academic mathematics. Baker (2005:6) suggests that mathematics is dominant in 
education because it has so much power to sort or filter, and 'appears to have achieved authority as a proxy for an indicator of "intelligence" .

Coben (2002) contrasts the 'use-value' of situated numeracy practices with the 'exchange-value' of classroom mathematics and associated qualifications. However, I think that the learners in my study value classroom mathematics for reasons that go beyond the desire for a qualification. Studies by Swain et al (2005) and Tomlin (2002) indicate that many adult learners aspire to the esoteric domain even when the adult numeracy curriculum restricts them to the functional domain. According to these studies by Swain et al (2005) and Tomlin (2002), this aspiration stems as much from issues of identity, self-esteem and personal and intellectual engagement as it does from the need to gain qualifications.

My interpretation of the mindmaps from Groups A, B and C is that the participants aspire to the cultural capital associated with mastery of classroom mathematics. They wish to succeed in areas which have eluded them in the past (such as memorising multiplication tables). I believe that the participants have represented on their mindmaps the curriculum they want to study - because it reflects their values and hopes for success in this 'high status' domain. Learners' interests are constructed by the curriculum rather than vice versa - they want to succeed in the challenge the existing curriculum sets them.

\section{Group D: A Process of Conscientization?}

Why were the mindmaps produced by Group D so different from those of Group A, B and C? Here I want to draw on Freire's ideas of dialogue and conscientization, which he sets against the oppressive or 'banking' approach to education, in which knowledge is 'deposited' in the 'domesticated' learner (Freire 1972, 1976). According to Freire, conscientization 'represents the development of the awakening of critical awareness' (1976:19).

All the participants in Group D were working at the same (relatively high) level of numeracy, and had been learning numeracy for at least four months. The group was small and mutually supportive, and the students tended to work closely together with lots of discussion amongst themselves. Moreover, they were all involved in other education and training, on courses leading to childcare and teaching assistant qualifications. As such, they are likely to have been exposed to, and to have become familiar with, discourses of educational policy and social justice. These may have been factors which encouraged them to discuss their own numeracy practices when drawing their mindmaps, and gave them the self-confidence to think beyond current curricular ideology. Bob worked until recently as a volunteer in a community-run café for young people in an area of social and 
economic deprivation, and he contributed enthusiastically to the discussion, perhaps reflecting this strong commitment to social justice.

I suggest that in Group D a process of conscientization had already begun for some members of the group, and that this process was furthered by the construction of their mindmaps and the accompanying discussion.

However, I feel that for other members of the group, this did not apply. For example, Janet is also in Group $\mathrm{D}$, and joined in some of the discussion. Careful examination of her mindmap (Figure 5, below) shows that it is quite different from Bob's (Figure 4, above). Janet first drew classroom topics such as ratio, percentages and measurements, and then added situated numeracy practices, such as mixing paint, shopping discounts and making curtains, as contexts for these skills. This matches the functional model of numeracy promoted by the discourse of UK government policy, in which autonomous skills are assumed to be transferable to contexts of use.

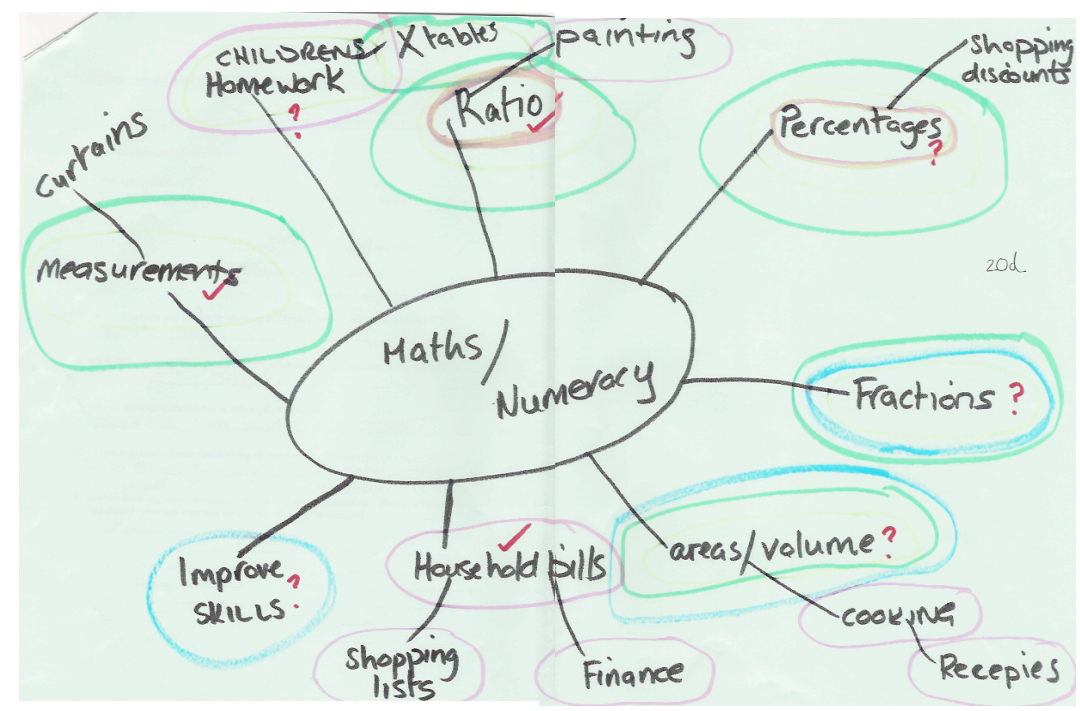

\section{Figure 5: Janet's mindmap. Janet starts with curriculum areas from classroom mathematics, and then adds social contexts for them.}

Freire suggests that learners may have internalised the 'values of the oppressors' and thus find themselves unable or unwilling to think critically about their situation and what actions are open to them to improve such a situation (Freire 1972:24). Is Janet actually representing the way she transfers her classroom numeracy skills to situated practice, or has she internalised the ideology of Skills for Life? 


\section{Limitations of the Study}

This was a small, exploratory study, carried out within a short timescale and with limited resources. There are a number of ways in which a similar project could be extended and improved.

Firstly, issues of power between teacher and learner, and between researcher and researched, will always be problematic in practitioner research. It is likely that at least some of the participants were anxious to give responses that would please or impress me. Some may, despite my assurances otherwise, have interpreted the exercise as an evaluation, and have wanted to give responses that reflected 'well' on my teaching. Carrying out a similar study on students who were not in my own classes might have produced different mindmaps - although I would not have had the same insights into the attitudes and beliefs of the participants.

Secondly, where participants discussed their mindmaps as they drew them, these conversations gave rich insights into their attitudes and beliefs which could only be jotted down in brief field notes. While the use of recording devices might have inhibited some participants, with others it would have yielded a rich source of data and an opportunity for triangulation.

Finally, although it would be an essentially different type of investigation, the mindmaps and discussions from Group D suggest that an ongoing action research project or focus group approach might begin a process of conscientization for the participants and yield a more radical set of ideas for a new curriculum.

\section{Conclusion}

Baker (2005) asks for the ideology behind curriculum development to be exposed and justified. How has curricular ideology become so naturalised that the majority of the adults in my investigation represented schoolroom mathematics on their mindmaps?

I suggest there are two ideologies at play here; the ideology of government policy, which positions numeracy as a set of transferable, functional skills; and the cultural ideology of the learners themselves, who perceive classroom mathematics as a high-status, esoteric measure of their own intelligence and value.

While my snapshot helps to illustrate these ideologies at work, it does not help us establish what an adult numeracy curriculum 'should' be - if such a conclusion is, indeed, attainable at all. Before we can ask how we should construct a curriculum which meets the needs and interests of adult numeracy learners, we need to understand how the interests and personal goals of those learners have been themselves constructed by the existing curriculum. 
At this point we meet the dilemma which all those who try to engage with Freire's philosophy will meet - how should we respond if students appear to want a 'banking' style of education? As educators, we may feel that our learners would be better served by a numeracy curriculum which empowers them and encourages them to think critically. However, if our learners want to learn mathematics as it is taught in the school classroom, and if they value achievement in this domain, then are we not enacting another form of oppression by imposing our own beliefs, however wellmeaning and liberal, on our learners? Freire himself recognised and commented on this problem:

They call themselves ignorant and say the 'professor' is the one who has knowledge and to whom they should listen. The criteria of knowledge imposed upon them are the conventional ones. 'Why don't you,' said a peasant participating in a culture circle, 'explain the pictures first? That way it'll take less time and won't give us a headache.' (Freire 1972:45)

\section{Endnotes}

1 Level 2 corresponds approximately to General Certificate of Secondary Education (GCSE) grades C-A*, the target level in England for students completing compulsory schooling at age 16 .

2 To protect anonymity, all names have been changed to pseudonyms chosen by the participants. This study was subject to ethical review by University of Sheffield, England.

\section{References}

Anderson-Inman, Lynne and Ditson, Leslie (1998) Computer-Based Concept Mapping: Promoting meaningful learning in science for students with disabilities, Information Technology and Disabilities 5 www.rit.edu/ easi/itd/itdv05.htm

Anderson-Inman, Lynne and Ditson, Leslie (1999) Computer-based Concept Mapping: A tool for negotiating meaning, Learning and Leading with Technology, vol 26, no 8, pp 7-13.

Baker, Carolyn (1982) Adolescent-adult Talk as a Practical Interpretive Problem, in Payne, G and Cuff, E, Eds, Doing Teaching: the Practical Management of Classrooms, Batsford, London, pp 104-125, cited in Silverman, D, Interpreting Qualitative Data, London, Sage

Baker, Carolyn (1997) Membership Categorization and Interview Accounts, in Silverman, D, Ed, Qualitative Research: Theory, method and practice, 130143. London, Sage

Baker, Dave (2005) Access and Equal Opportunities: Is it sufficient for maths/numeracy, development and social justice?, Reepham, Uppingham Seminar 2005. 
Baxter, Mark, Leddy, Eamonn, Richards, Liz, Tomlin, Alison, Wresniwiro, Topo and Coben, Diana (2006) Measurement Wasn't Taught When They Built the Pyramids - Was it? National Research and Development Council, London.

Benn, Rosanne (2001) All for One and One for All: Citizenship and mathematics education, in Schmitt, MJ and Safford-Ramus, K, Eds, A Conversation between Researchers and Practitioners, Adults Learning Mathematics - 7, Proceedings of ALM-7 the Seventh International Conference of Adults Learning Mathematics - A Research Forum Cambridge, National Center for the Study of Adult Learning and Literacy (NCSALL), Harvard University Graduate School of Education, in association with ALM, pp. 109-115.

Bernstein, Basil (1975) Class, Codes and Control, Vol 3, Towards a Theory of Educational Transmissions, Routledge and Kegan Paul, London.

Bernstein, Basil (1996) Pedagogy, Symbolic Control and Identity, Taylor \& Francis, London.

Bourdieu, Pierre (2003) The Forms of Capital, in Ball, S, Ed, The Routledge Falmer Reader in Sociology of Education, Routledge Falmer, London, pp. 1529 (English version first published in Richardson, J (1986) Handbook for Theory and Research for the Sociology of Education, pp 241-258).

Basic Skills Agency (BSA) (2001) The Adult Numeracy Core Curriculum, Basic Skills Agency, London.

Buzan, Tony (1993) The Mind Map Book: Radiant thinking - The major evolution in human thought, BBC Books, London.

Goben, Diana (2002) Use Value and Exchange Value in Discursive Domains of Adult Numeracy Teaching, Literacy and Numeracy Studies: An international journal in the education and training of adults, vol 11, no 2, pp 25-35.

Coben, Diana (2006) The social-cultural approach to adult numeracy: Issues for policy and practice, in Tett, L, Hamilton. M and Hillier, Y, Eds, Adult Literacy, Numeracy and Language: Policy, practice and research, Open University Press, Maidenhead.

Cohen, Louis, Manion, Laurence, and Morrison, Keith (2007) Research Methods in Education, RoutledgeFalmer, London.

Department for Education and Skills (DfES) (2001) Delivering Skills for Life: The national strategy for improving adult literacy and numeracy skills, Department for Education and Skills (DfES), London.

Dowling, Paul (1998) The Sociology of Mathematics Education: Mathematical myths/pedagogic texts, Falmer Press, London.

Edwards, Richard and Usher, Robin (2000) Globalisation and Pedagogy: Space, place and identity, Routledge, London, cited in Mannion, $\mathrm{G}$ and Ivanič, $\mathrm{R}$ (2007) Mapping literacy practices: theory, methodology, methods, International Fournal of Qualitative Studies in Education, vol 20, no 1. pp 15-30.

Evans, Jeff and Tsatsaroni, Anna (2000) Mathematics and its publics: texts, contexts and users, Social Epistemology, vol 14, no 1, pp 55-68.

Freire, Paolo (1972) Pedagogy of the Oppressed, Harmondsworth, Penguin. 
Freire, Paolo (1976) Education: The Practice of Freedom, translated by Bergman Ramos, M, Writers and Readers, London cited in Coben, D, O'Donoghue, J and FitzSimons, G, eds, (2000) Perspectives on Adults Learning Mathematics, Dordrecht, Kluwer Academic Publishers The Netherlands.

Kress, Gunther and Mavers, Diane (2004) Social semiotics and multimodal texts, in Somekh, B and Lewin, C, Research Methods in the Social Sciences London, pp 172-179.

Kress, Gunther, Jewitt, Carey, Bourne, Jill, Franks, Anton, Hardcastle, John, Jones, Ken (2004) English in Urban Classrooms: A multimodal perspective in teaching and learning, Routledge, London.

Lave, Jean (1988) Cognition in Practice, Cambridge University Press, Cambridge.

Lerman, Stephen (2000) The Social Turn in Mathematics Education Research, in Boaler, J, ed, International Perspectives on Mathematics Education, Ablex, Westport, CT pp 19-44.

Mannion, Greg and Ivanič, Roz (2007) Mapping Literacy Practices: Theory, methodology, methods, International Journal of Qualitative Studies in Education , vol 20, no 1, pp 15-30.

Mavers, Diane and Somekh, Bridget with Restorick, Jane (2002) 'Interpreting the Externalised Images of Pupils' Conceptions of ICT: Methods for the analysis of concept maps', Computers and Education, vol 38, no 1-3, pp 187207.

Novak, Joseph and Gowin, Bob (1984) Learning How to Learn, Cambridge University Press, New York.

Oughton, Helen (2007) Constructing the 'Ideal Learner': A Critical Discourse Analysis of the adult numeracy core curriculum, Research in PostCompulsory Education, vol 12, no 2, pp 259-275.

Papen, Uta (2005) Adult Literacy as a Social Practice: More than skills, Routledge, Oxford.

Pearson, Matthew and Somekh, Bridget (2000) Concept Mapping as a Research Tool: A study of primary children's representations of ICT, British Educational Research Association Conference, Cardiff accessed 18 August 2008 www.leeds.ac.uk/educol/newnews.htm.

Silverman, David (2000) Doing Qualitative Research: A practical handbook, Sage London.

Silverman, David (2001) Interpreting Qualitative Data: Methods for analysing talk, text and interaction, Sage, London.

Swain, Jon (2005) 'Beyond the Daily Application': Motivations for adults attending numeracy classes, Research in Post-Compulsory Education, vol 10, no 3, pp 305-323.

Swain, Jon, Baker, Elizabeth, Holder, Deborah, Newmarch, Barbara and Coben, Diana (2005) Beyond the Daily Application: Making numeracy teaching meaningful to adult learners, National Research and Development Council (NRDC), London.

Tomlin, Alison (2002) 'Real life' in everyday and academic maths, in Valero, $\mathrm{P}$ and Skovsmose, O, eds, Proceedings of the 3rd International MES Conference, Copenhagen, Gentre for Research in Learning Mathematics, pp 1-9. 
Tomlin, Alison, Baker, Dave and Street, Brian (2002) Home and School Numeracy Practices: Where are the borders and overlaps?, in Valero, $\mathrm{P}$ and Skovsmose, $\mathrm{O}$, eds, Proceedings of the 3rd International MES Conference, Copenhagen, Centre for Research in Learning Mathematics, pp 480-488. 
Appendix Table 1: Summarising the results of my analysis of the learners' mind maps. The letters in the table show the reasons participants gave for wanting to study each numeracy topic, indicated by colour-coding on the mind maps. The letters stand for: $\mathrm{e}($ pink $)=$ 'needed for everyday life'; $\mathrm{w}($ orange $)=$ 'needed for work', $\mathrm{c}$ (yellow $)=$ 'needed to help your children';

$q($ green $)=$ 'needed for a qualification'; $p($ blue $)=$ 'topics you have always wanted to understand'

\begin{tabular}{|c|c|c|c|c|c|c|c|c|c|c|c|c|c|c|c|c|c|c|c|c|c|c|c|c|c|c|c|c|c|}
\hline \multirow[b]{3}{*}{ 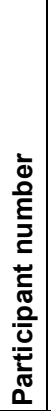 } & \multirow[b]{3}{*}{$\begin{array}{l}\text { 음 } \\
\frac{0}{0}\end{array}$} & \multirow[b]{3}{*}{$\stackrel{0}{8}$} & \multirow[b]{3}{*}{$\stackrel{\mathbf{L}}{\mathbf{\Sigma}}$} & \multirow{3}{*}{ 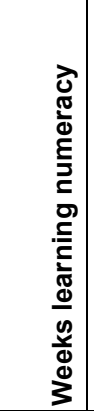 } & \multirow[b]{3}{*}{$\stackrel{\Phi}{\Phi}^{\bar{\Phi}}$} & \multicolumn{24}{|c|}{ Classroom Numeracy } \\
\hline & & & & & & \multicolumn{15}{|c|}{ Whole numbers } & \multicolumn{3}{|c|}{ Fractions } & \multicolumn{6}{|c|}{ Space and shape } \\
\hline & & & & & & 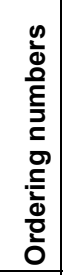 & 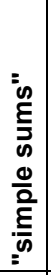 & 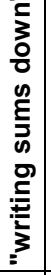 & 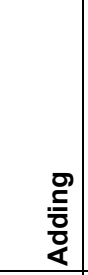 & 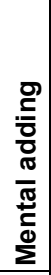 & 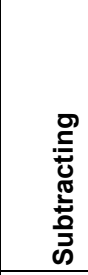 & 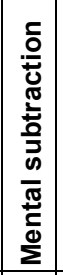 & 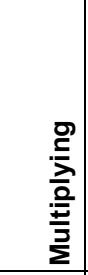 & 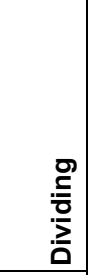 & $\begin{array}{l}\frac{5}{0} \\
\frac{0}{0} \\
\frac{1}{0} \\
0 \\
0 \\
0\end{array}$ & $\begin{array}{l}\text { g } \\
\frac{d}{0} \\
\frac{\pi}{10}\end{array}$ & 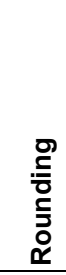 & 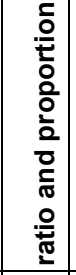 & 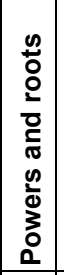 & \begin{tabular}{|l|}
$\frac{\pi}{0}$ \\
$\frac{0}{0}$ \\
$\frac{0}{\alpha}$ \\
\end{tabular} & 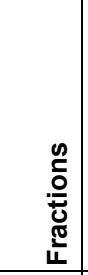 & 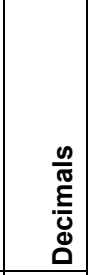 & 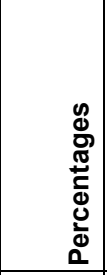 & 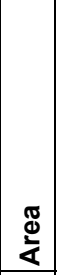 & 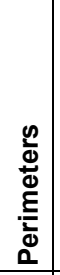 & $\frac{\stackrel{0}{\Xi}}{3}$ & $\frac{\text { o }}{\frac{0}{5}}$ & 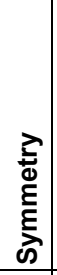 & $\begin{array}{l}\stackrel{\infty}{0} \\
\frac{0}{\pi} \\
\frac{5}{\omega}\end{array}$ \\
\hline 01 & A & $21-30$ & $\mathrm{f}$ & $2-8$ & E3 & & & & & & wp & & $q$ & qp & & $\mathrm{p}$ & & & & & $\mathrm{p}$ & & & & & & & & \\
\hline 02 & A & $21-30$ & $\mathrm{f}$ & $2-8$ & E3 & & & & & & eqp & & $q$ & eqp & & $\mathrm{qp}$ & & & & & $q p$ & & & & & & & & \\
\hline 03 & $A$ & $0-20$ & $f$ & $2-8$ & L1 & ecq & & & ewcq & & ewcq & & ewcq & ewcq & & & ecq & ecq & & & & ecqp & ewcpq & & & ewc & ewc & & ewc \\
\hline 04 & $\mathrm{~A}$ & $41-50$ & $f$ & $2-8$ & L1 & ecq & & & ewcq & & ewcq & & ewcq & ewcq & $p$ & & ecq & ecq & & & & ecqp & ewcq & & & & ewc & & ewc \\
\hline 05 & $\mathrm{~B}$ & $21-30$ & $f$ & $8-26$ & L1 & & & & ecq & & & & & & & & & & & & ecqp & ecqp & ecqp & & & & & & \\
\hline 06 & $\mathrm{~B}$ & $21-30$ & $f$ & $8-26$ & L2 & & & & & & & & ecpq & ecq & & ep & & $q$ & & & $q p$ & $\mathrm{n}$ & ecp & & & & & & \\
\hline 07 & $\mathrm{~B}$ & $21-30$ & $f$ & $8-26$ & L1 & & & & ecq & & ecq & & & & & & & & & & ecqp & $\mathrm{cp}$ & ecqp & & & & & & \\
\hline 08 & $\mathrm{~B}$ & $21-30$ & $\mathrm{f}$ & $2-8$ & L1 & & & & & & & & wcq & & & & & $p$ & & $p$ & wcq & wcq & wcq & & & & & & \\
\hline 09 & $\mathrm{~B}$ & $31-40$ & $f$ & $8-26$ & L2 & & & & & & & & & & & & & & & & ep & ep & ep & ep & ep & & & & \\
\hline 10 & $\mathrm{~B}$ & $31-40$ & $\mathrm{~m}$ & $26-52$ & L2 & & & & & & & & & & & & & $\mathrm{e}$ & & & ep & & ep & & & ep & ep & & ep \\
\hline 11 & $\mathrm{C}$ & $31-40$ & $f$ & $2-8$ & E3 & & & & & $\mathrm{e}$ & cqp & & cqp & cqp & cqp & $\mathrm{cpq}$ & & & & & & & cqp & & & & & & \\
\hline 12 & $C$ & $41-50$ & $f$ & $26-52$ & L1 & & & & & & & & & & & & & & & & & & $\mathrm{cp}$ & & & & & & \\
\hline 13 & $\mathrm{C}$ & $0-20$ & $\mathrm{~m}$ & $2-8$ & L1 & & & & $\mathrm{e}$ & & & & $\mathrm{e}$ & & & & & & & qp & w & & w & & & & & & \\
\hline 14 & $\mathrm{C}$ & $51-60$ & $\mathrm{~m}$ & $2-8$ & L1 & & & & & & & & & & & & & & & & & & & & & & & & \\
\hline
\end{tabular}


Table 1 Gontinued

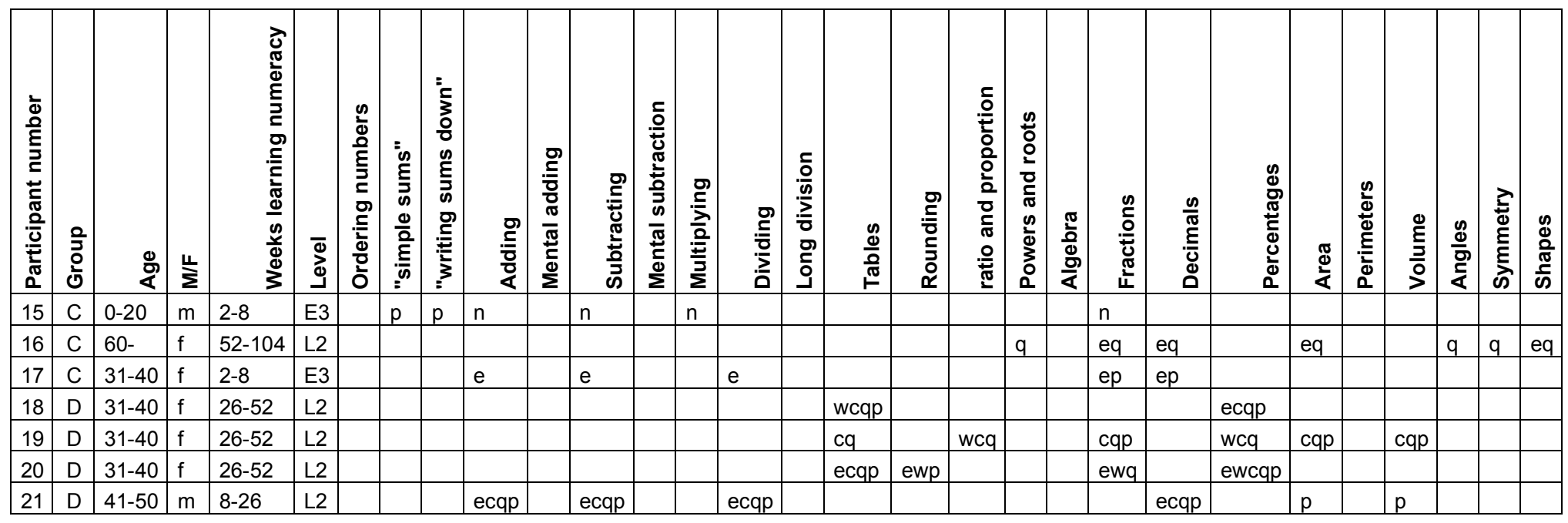




\section{Table 2: Summarising the results of my analysis of the learners' mind maps}

The letters in the table show the reasons participants gave for wanting to study each numeracy topic, indicated by colour-coding on the mind maps. The letters stand for: $\mathbf{e}$ (pink) = 'needed for everyday life'; $\mathbf{w}$ (orange) = 'needed for work'; c (yellow) = 'needed to help your children';

$\mathbf{q}$ (green) $=$ 'needed for a qualification'; $\mathbf{p}$ (blue) $=$ 'topics you have always wanted to understand'

\begin{tabular}{|c|c|c|c|c|c|c|c|c|c|c|c|c|c|c|c|c|c|c|c|c|c|c|c|c|c|c|c|c|c|c|}
\hline \multicolumn{10}{|c|}{ Classroom Numeracy (contd) } & \multirow{2}{*}{\multicolumn{13}{|c|}{ Situated Practices }} & \multirow{2}{*}{\multicolumn{8}{|c|}{ Motivations }} \\
\hline \multicolumn{7}{|c|}{ Measurements } & \multicolumn{3}{|c|}{ Data Handling } & & & & & & & & & & & & & & & & & & & & & \\
\hline 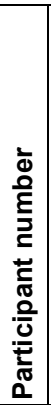 & 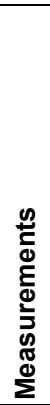 & 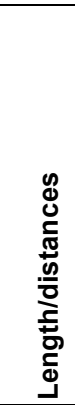 & 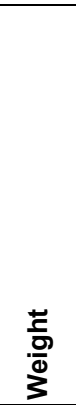 & $\begin{array}{l}\vec{i} \\
\text { i } \\
\frac{0}{0} \\
\frac{0}{0} \\
0\end{array}$ & 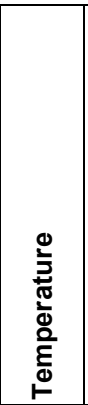 & 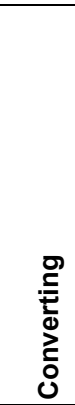 & 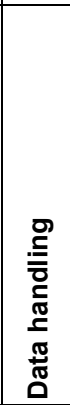 & $\begin{array}{l}\frac{n}{2} \\
\frac{c}{0} \\
\frac{0}{0} \\
0\end{array}$ & 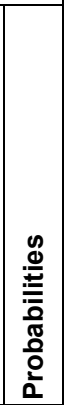 & 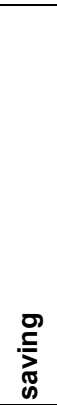 & 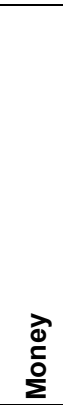 & 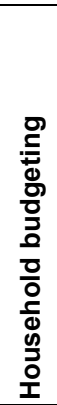 & 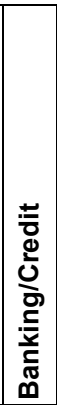 & 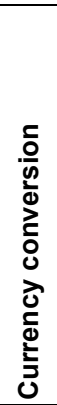 & $\begin{array}{l}\frac{0}{0} \\
\frac{\overline{0}}{0} \\
\frac{0}{0}\end{array}$ & 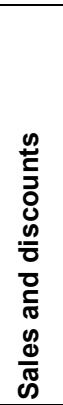 & $\grave{\overline{0}}$ & 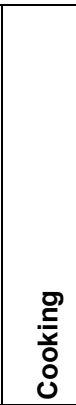 & 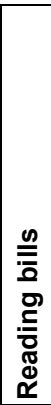 & \begin{tabular}{|l} 
\\
\\
$\vdots$
\end{tabular} & 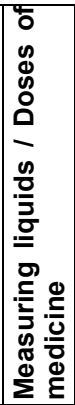 & 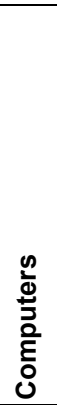 & 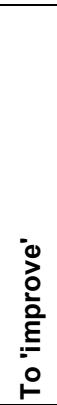 & 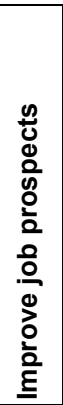 & 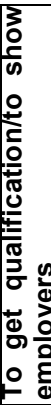 & 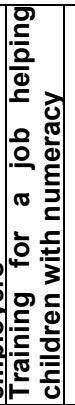 & 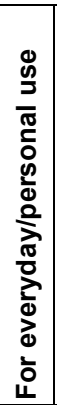 & 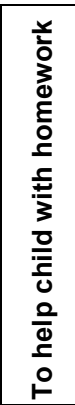 & 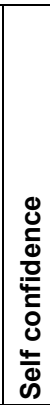 & 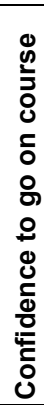 \\
\hline 01 & & $\mathrm{qp}$ & wqp & $\mathrm{qp}$ & & & & wqp & & & & & & & & & & & & & & & & & & & & & & \\
\hline 02 & & & eqp & eqp & & & & $\mathrm{ep}$ & & & & & & & & & & & & & & & & & & & & & & \\
\hline 03 & & ewc & ewc & & & & ecq & ecq & & & & & & & & & & & & & & & & & & & & & & \\
\hline 04 & & ewc & ewc & ewc & & & ecq & ecq & & & & & & & & & & & & & & & & & & & & & & \\
\hline 05 & & & & ecqp & ecqp & & & & & & & & & & & & & & & $\mathrm{n}$ & $q$ & & & & & & & & & \\
\hline 06 & & & & $w q$ & & eq & & & & & & & & & & & & & & & wcq & & & & & & & & & \\
\hline 07 & & & ecqp & & eqp & & & & & & & & & & & & & & & $\mathrm{n}$ & & & & & & & & & & \\
\hline 08 & & ecp & ecp & ecp & & & & & & & & & & & & & & & & & & & & & & & & & & \\
\hline 09 & & ep & ecp & & & & & & & & & & & & & & ep & ecp & ep & & & & & & & & & ecqp & & \\
\hline 10 & & ep & & & & & & & & & & & & & & & & & & & & & & & & & & & & \\
\hline 11 & & wq & & & & & & & & & e & & & & cqp & & & & & & & & e & & $q$ & & e & c & & $\mathrm{n}$ \\
\hline 12 & & & & & & & & & & & & & & & & & & & & & & & & & & & & & & \\
\hline
\end{tabular}


Table 2 Gontinued

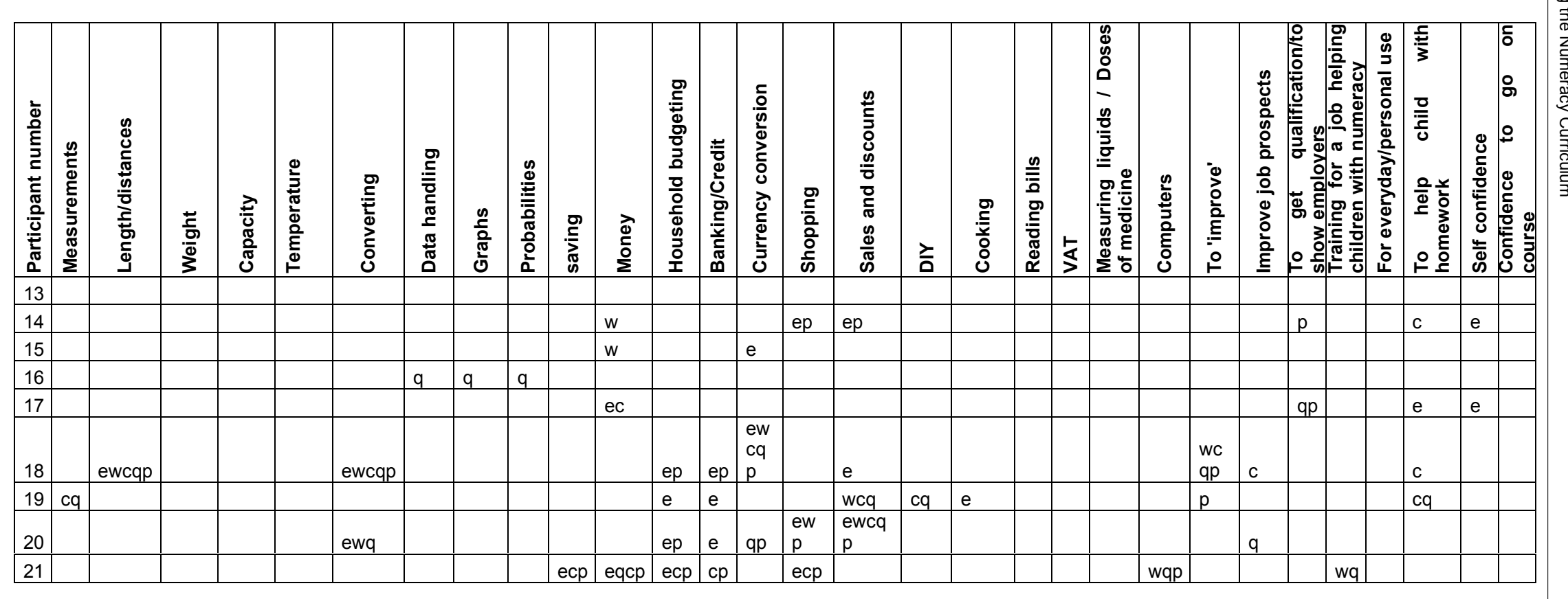


